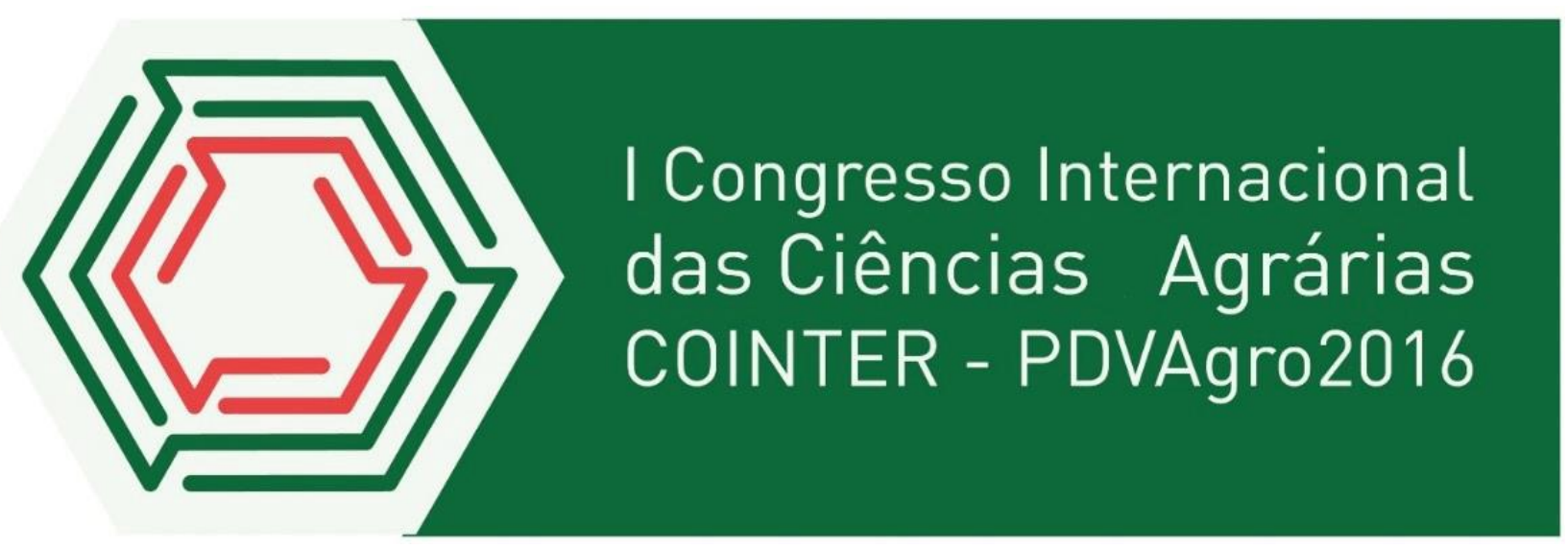

\title{
TREINAMENTO DE BOAS PRÁTICAS DE FABRICAÇÃO NO PROCESSAMETO MÍNIMO DE FRUTAS E HORTALIAS
}

\author{
Apresentação: Pôster
}

\begin{abstract}
Vanessa Ribeiro de Lima Fidelis ${ }^{1}$; Alcimar de Melo Dias ${ }^{2}$; Luciane Maria dos Anjos Bezerra ${ }^{3}$; Mônica Mauricio do Nascimento ${ }^{4}$, Welliton Barros de Magalhães ${ }^{5}$
\end{abstract}

\section{Introdução}

As Boas Práticas de Fabricação (BPF) representam uma importante ferramenta da qualidade para o alcance de níveis adequados de segurança dos alimentos. Sua adoção é um requisito da legislação vigente e faz parte dos programas de garantia da qualidade do produto final. As boas práticas devem ser aplicadas desde a recepção da matéria prima, processamento, até a expedição de produtos, contemplando os mais diversos aspectos da indústria, que vão desde a qualidade da matéria-prima e dos ingredientes, incluindo a especificação de produtos e a seleção de fornecedores, à qualidade da água (MACHADO, 2015).

Um programa de BPF é dividido nos seguintes itens: instalações industriais; pessoal; operações; controle de pragas; controle da matéria-prima; registros e documentação e rastreabilidade. Além das questões que envolvem a qualidade dos alimentos, as BPF possibilitam um ambiente de trabalho mais eficiente, contribuindo para a eficácia do processo de produção. São necessárias para controlar possíveis fontes de contaminação cruzada e para garantir que o produto

\footnotetext{
${ }^{1}$ Aluno do curso Bacharelado em agroindústria, UFPB E-mail: vribeiro_ribeiro@ hotmail.com

${ }^{2}$ Aluno do curso Bacharelado em agroindústria, UFPB E-mail: alcymardias@gmail.com

${ }^{3}$ Aluno do curso Bacharelado em agroindústria, UFPB E-mail: lucianemariaufpb@gmail.com

${ }^{4}$ Aluno do curso Bacharelado em agroindústria, UFPB E-mail: monicamauricio5@ gmail.com Orientador/Técnico administrativo - UFPB/CCCHSA - Universidade Federal da Paraíba, e-mail: welliton.barros@ufv.br.
} 
atenda às especificações de identidade e de qualidade. As instruções contidas nessas informações técnicas servirão de base para a elaboração do Manual de BPF (MACHADO, 2015).

Essas informações podem ser transcritas diretamente no referido manual, depois de adaptadas à realidade do estabelecimento. Para a garantia de qualidade dos produtos oriundos da agroindústria familiar, as exigências são semelhantes às de outras escalas de produção. A qualidade sensorial desses produtos, já percebida pelos consumidores, deve vir acompanhada da qualidade sanitária, para que possam demonstrar o seu diferencial, tão desejado pelo setor produtivo. (MACHADO, 2015).

Este trabalho teve como objetivo transferir aos filhos dos agricultores as boas práticas de fabricação no processamento mínimo de frutas e hortaliças.

\section{Fundamentação Teórica}

Internacionalmente conhecidas como Good Manufactures Pratices (GMP), as BPF são um conjunto de regras, procedimentos que estabelece o correto manuseio dos alimentos e princípios, aplicados desde a matéria-prima até o produto final. São normas para atingir um determinado padrão de identidade e qualidade de um serviço e/ou produto na área de alimentos, cuja efetividade e eficácia são avaliadas através de investigações, aplicação do check-list e/ou inspeções constantes (JUNIOR, 2007).

A partir de 2002 e 2004 entrou em vigor no Brasil a RDC No 275 e 216, respectivamente, com o objetivo de estabelecer procedimentos operacionais padronizados de Boas Práticas Fabricação buscando garantir as condições higiênico-sanitárias do alimento preparado. Com a criação destas RDCs, todas as empresas e indústrias de alimentos, deveriam ter conhecimento de sua importância, pois são procedimentos que devem ser adotados nas UPR para garantir a qualidade e a conformidade dos alimentos de acordo com a legislação (BRASIL, 2004).

Segundo a International Fresh-Cut Producers Association (IFPA, 2005), produtos minimamente processados são definidos como qualquer fruta ou hortaliça, ou ainda qualquer combinação delas, que foi alterada fisicamente a partir de sua forma original, embora mantenha o seu estado fresco. Independentemente do tipo, ele é selecionado, lavado, descascado e cortado, resultando num produto $100 \%$ aproveitável que, posteriormente, é embalado ou pré-embalado.

No processamento mínimo, as barreiras para eliminação de microrganismos são poucas, constituindose as chamadas tecnologias de barreiras ou obstáculos, que incluem, principalmente, a lavagem, o uso de sanificantes, as embalagens em atmosfera modificada e a refrigeração 
(BERBARI et al., 2001).

\section{Metodologia}

O trabalho foi desenvolvido no setor de agricultura pertencente à Universidade Federal da Paraíba (UFPB), Campus III-Bananeiras/PB, com 16 participantes, filhos de agricultores e alunos do curso de bacharelado em agroindústria.

Foi utilizada uma sequência didática com: A aplicação de um questionário e treinamento com o repasse da boas praticas de fabricação (BPF) no processamento mínimo de frutas e hortaliças. O treinamento foi feito após a aplicação dos questionários no Laboratório de Pesquisa e Desenvolvimento de Produtos Frutohortícolas pertencente ao Centro de Ciências Humanas Sociais e Agrárias - Bananeiras/PB.

Figura 1- Modelo de questionário proposto para treinamento de boas práticas de fabricação no processamento mínimo de frutas e hortaliças, Bananeiras - PB, CCHSA/UFPB, 2016.

\section{Questionário}

Idade:

Sexo:

1. Você é um produtor de frutas e hortaliças?

$\operatorname{Sim}($ ) Não ( )

2. Consome frutas e hortaliças?

Sim ( ) Não ( ) Raramente ( )

3. Você sabe o que é Boas práticas de fabricação (BPF)?

$\operatorname{Sim}($ ) Não ( )

4. Teria interesse de aprender sobre a técnica de Boas práticas de fabricação (BPF)?

$\operatorname{Sim}($ ) Não ( )

\section{Resultados e Discussões}

A sequência didática utilizada foca na percepção e capacitação, a mesma pode ser compreendida como um conjunto de atividades ligadas entre si, planejadas para ensinar um 
conteúdo, etapa por etapa. Organizadas de acordo com os objetivos que o professor/extensionista quer alcançar para a aprendizagem de seus alunos, elas envolvem atividades de aprendizagem e de avaliação (DOLZ, NOVERRAZ e SCNEUWLY, 2004).

A sequência didática foi aplicada da seguinte forma: a primeira atividade deste estudo foi à aplicação de um questionário com 4 questões, onde foi possível averiguar o conhecimento que os mesmos dispunham sobre o assunto. Mediante a analise dos questionários pode ser observado, dentro do universo pesquisado algumas informações bem pertinentes ao assunto. Em seguida foram realizados treinamentos com os filhos dos agricultores familiares e alunos do curso de bacharelado em agroindústria com o repasse da tecnologia do processamento mínimo. Quando questionado se são produtores de frutas, num total de $40 \%$ dos filhos dos agricultores responderam que sim e apenas $60 \%$ responderão que não, esses $60 \%$ estão inclusos no percentual de produtores de hortaliças e apenas $1 \%$ não é produtor de frutas, ou seja, 90\% dos produtores entrevistados têm produção mista (frutas e hortaliças), caracterizados com uma produção anual, com diferentes produtos durante todo o ano.

Em relação o consumo de frutas, num total de $50 \%$ respondeu que sim e $50 \%$ responderam que não. Tratando em relação o conhecimento sobre as boas práticas do processamento mínimo $30 \%$ disseram sim e $60 \%$ responderam que não, mediante a estes primeiros questionamentos o interesse de aprender sobre esta técnica foram no total de $100 \%$.

\section{Conclusão}

Pode se concluir que este trabalho, foi de suma importância, haja vista que os participantes mostraram interesse em repassar e aplicar os conhecimentos adquiridos em sua comunidade.

\section{Referências}

BERBARI, S. A. G.; PASCHOALINO, J. E.; SILVEIRA, N. F. A. Efeito do cloro na água de lavagem para desinfecção de alface minimamente processada. Ciência e Tecnologia de Alimentos, Campinas, v. 21, n. 2, p. 197-201, maio/ago. 2001.

BRASIL. Resolução RDC no 275 de 21 de outubro de 2002 da Secretária Nacional de Vigilância Sanitária do Ministério da Saúde. 2002.

BRASIL. Resoluçao RDC $\mathrm{n}^{\circ} 216$ de 15 de setembro de 2004. Dispõe sobre regulamento técnico de boas práticas para serviços de alimentação. 2004. p. 1-9. 
DOLZ, NOVERRAZ e SCNEUWLY. Sequências didáticas para o oral e a escrita: apresentação de um procedimento. In. DOLZ \& SHNEUWULY (orgs) Gêneros Orais e Escritos na Escola. São Paulo: Mercado de Letras, 2004.

IFPA. International fresh-cut produce association. Disponível em: <http://www.fresch-cuts.org.> Acesso em: 01 out. 2016.

JUNIOR E. A. da S. Manual de Controle Higiênico-sanitário em Alimentos. 6th ed. Varela, editor. São Paulo; 2007.

MACHADO, L. P. M.; MAURO. A. de S. D.; PINTO, V.P. Boas Práticas de Fabricação (BPF). Embrapa Agroindústria de Alimentos Rio de Janeiro, RJ 2015. 